\title{
ENUNCIADOS FIGURADOS EN TEXTOS TURÍSTICOS DEL ÁMBITO INSTITUCIONAL: ANÁLISIS SEMÁNTICO- PRAGMÁTICO EN FOLLETOS Y ANUNCIOS DE LA CAMPAÑA REGIÓN DE MURCIA NO-TYPICAL
}

\author{
Carmen Sánchez Manzanares \\ Universidad de Murcia \\ carmensm@um.es
}

Recibido: $19 / 05 / 2015$

Aceptado: 08/09/2015

\section{Resumen}

El propósito de este artículo es el análisis de la funcionalidad en textos turísticos de enunciados de sentido figurado. Para ello hemos seleccionado un conjunto de textos emitidos por la Comunidad Autónoma de la Región de Murcia en el marco de una campaña para la promoción de la Región como destino turístico. La marca del destino en dicha campaña es Región de Murcia no-typical y en torno a ella se articulan una serie de textos en los que se tienen enunciados que cumplen con la finalidad propia de un eslogan publicitario. Nos centramos principalmente en la función comunicativa de metáfora y metonimia para la construcción del sentido figurado, por lo cual realizamos un análisis tanto semántico como pragmático de estos enunciados. Nuestra hipótesis de partida es que mediante estos procedimientos se proyecta una imagen del destino turístico que implica para su interpretación la activación de procesos cognitivos y de valores afectivos del destinatario. Con ello se guía la elección del producto que se promociona, pues la imagen así creada conecta los llamados atractivos turísticos del lugar con las expectativas personales del turista potencial, tanto en lo cognitivo como en lo afectivo.

PALABRAS CLAVE: enunciado figurado, texto turístico, metáfora, metonimia, función comunicativa
\end{abstract}

\begin{abstract}
The purpose of this article is to analyze functionality in statements with a figurative meaning in tourist texts. In order to do so, we have selected a group of texts published by the Region of Murcia as part of a campaign to promote the region as a tourist destination. The motto in this campaign is Region of Murcia no-typical, and around it a number of texts are articulated- all of which fulfill the expected aim of a marketing slogan. We mainly focus on the communicative function of metaphors and metonymies to construct a figurative meaning, so we carry out both a semantic and pragmatic analysis of the selected statements. Our hypothesis considers that these procedures project an image of the tourist destination that relies on the recipients cognitive processes and emotional values for its interpretation. These techniques therefore lead the choice of the marketed product, as the constructed image links the tourist appeals of the region with the expectations of the future tourist, both in cognitive and emotional areas.
\end{abstract}

KEYWORDS: figurative statement, tourist text, metaphor, metonymy, communicative function

\section{Introducción}

En este artículo nos proponemos abordar cómo se configuran los enunciados de sentido figurado, principalmente metafóricos y metonímicos, en el discurso para la promoción de un destino turístico emitido en el ámbito institucional y analizar cuál es la finalidad 
de estos enunciados, qué función cumplen con respecto a la finalidad global del discurso turístico. El concepto de turismo ha evolucionado y la publicidad de un lugar se centra actualmente en las vivencias y emociones que puede ofrecer al potencial turista. Metáfora y metonimia posibilitan una imagen del destino turístico original y subjetiva, a la vez que conforman un enunciado atractivo y sorprendente. Mediante estos procedimientos se consigue la adhesión o captación de la voluntad del destinatario del texto, tanto a nivel intelectual como a nivel afectivo, pues se crean o refuerzan expectativas sobre el destino turístico y se cambian creencias o actitudes frente al producto que se promociona. La construcción del sentido figurado, en general, responde en estos enunciados a una estrategia discursiva persuasiva, propia del texto publicitario, orientada a intervenir sobre la elección del turista y a determinar su actuación. Sin embargo, lo llamativo es cómo se liga esta orientación a la práctica descriptiva natural del texto turístico mediante los procesos metafóricos y metonímicos.

Nuestro análisis del sentido figurado de un enunciado integra la perspectiva tanto de la semántica como de la pragmática ${ }^{1}$, pues consideramos tanto la semanticidad como la intención comunicativa y los factores contextuales. La conjunción de los distintos enfoques nos proporciona un marco teórico y herramientas metodológicas para el análisis de los procedimientos y para la determinación de la funcionalidad de los enunciados figurados en los textos turísticos. De esta manera, nos proponemos obtener resultados clarificadores sobre la producción e interpretación de sentido en este tipo de textos.

En el ámbito de la promoción institucional turística se ha producido, como en otros ámbitos, una apuesta por la difusión de textos en Internet, pues es incuestionable el mayor alcance de la difusión, sobre todo si se piensa en destinatarios internacionales. Por esta razón, hemos seleccionado para el análisis documentos emitidos durante una campaña turística de la Región de Murcia publicados en la web de la Consejería de Cultura y Turismo de esta Región (http://goo.gl/al1KCk). También analizamos otros textos que formaban parte de la campaña, como los que se difundían en grandes lonas que se exhibían en fachadas de edificios principales y los anuncios que se distribuían en prensa.

El tipo textual que seleccionamos para la constitución de nuestro corpus es el que se enmarca en las producciones textuales para la descripción y promoción del destino turístico; dentro de estas producciones, los textos seleccionados son folletos y anuncios. Mientras que el folleto constituye un macrogénero del turismo, el anuncio es un género del ámbito de la publicidad con características específicas cuando se insertan en el ámbito del turismo. Todos ellos pertenecen a la familia de los géneros institucionales. Nos basamos para esta caracterización tipológica en la agrupación que presenta Calvi (2010) de producciones textuales del turismo, correspondientes a las distintas prácticas sociales, y en su clasificación de géneros textuales ${ }^{2}$.

1 El enfoque de la lingüística cognitiva es también rentable, como muestran Barcelona y Rocamora en su trabajo: "El argot turístico y la teoría cognitiva de la metáfora y la metonimia" (2000).

2 Como señala Calvi (2010: 10), el turismo como actividad profesional ha promovido el desarrollo de géneros textuales específicos. 
La campaña turística a la que nos referimos, de tres años de duración, desde enero de 2009 a enero de $2012^{3}$, se concibió de una forma inusual contando para su desarrollo, aparentemente, con la colaboración ciudadana. Daremos cuenta de la idea matriz de la campaña que motivó esta participación y dio lugar al lema Región de Murcia no-typical para situar los textos seleccionados, todos ellos interrelacionados y vertebrados por esta idea.

\section{Presentación del corpus, hipótesis y objetivos}

\subsection{Corpus}

Hemos constituido nuestro corpus seleccionando de la campaña Región de Murcia no-typical dos tipos de textos promocionales que nos interesan por su proximidad al texto publicitario:

- los folletos que se presentan en la web de la Consejería, que pertenecen a una categoría superior dentro de los géneros del turismo y que, de acuerdo con Calvi (2010: 23), se caracterizan por un lenguaje muy cercano al publicitario;

- los anuncios que se distribuyen en prensa y los carteles en la vía pública, que se categorizan como textos publicitarios que, como hace notar Calvi (2010: 25), se recontextualizan en el ámbito turístico adquiriendo rasgos específicos, especialmente cuando están promovidos por las instituciones.

En estos tipos es ostensible la intención persuasiva, como en los textos publicitarios, y, como en ellos también, la metáfora y otros usos figurados involucran una representación imaginativa de atributos del producto que se promociona. La actual tendencia de la publicidad al sentido figurado se debe, además, a la implicación cognitiva y afectiva del receptor y ello es visible también en estos textos seleccionados. Como observa Calvi (2010: 19), la peculiaridad del producto requiere unos modelos textuales propios, que entroncan con distintas tradiciones discursivas.

El primer conjunto de documentos, los folletos, se disponían en una sección de la web titulada Qué hacer, en la que se tenía acceso a quince enlaces para la promoción de distintas categorías turísticas (Sol y Playa, Rural, Cultura, etc.). Como observa González (2012: 21), la hipertextualidad da coherencia a estos distintos enlaces de la sección y, por otra parte facilita que la web funcione como repositorio de documentos de interés. Estos folletos, bastante extensos y de algún modo similares a pequeñas guías turísticas, se presentaban con una titulación siempre encabezada por Hoy en la que se condensaba el aspecto que se privilegiaba del producto turístico que se promocionaba; así, para Murcia como destino de sol y playa, el título del folleto era: Hoy me siento pez. Se disponía así de varios accesos para conocer la oferta turística según la apetencia puntual del usuario. Además se contaba con un folleto de carácter general titulado: Hoy estás en la Región de Murcia.

3 Esta campaña se inicia en enero de 2009 y la siguiente se presenta públicamente en enero de 2012. No obstante, el portal de Internet no se renueva hasta dos años después de presentarse la nueva campaña, por lo que los documentos que analizamos han estado accesibles hasta febrero de 2014. Tenemos, por tanto, que señalar el desfase entre la recuperación de la información turística en el hipertexto por parte del usuario y la recepción del discurso promocional de la campaña vigente. 


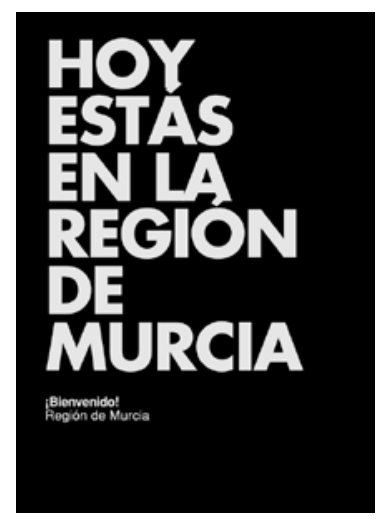

Imagen 1

Los folletos que seleccionamos forman parte, como antes señalamos, de las producciones textuales dedicadas a la descripción y promoción de lugares turísticos, en este caso emitidos por una institución pública ${ }^{4}$. En este bloque en el que se encuadran, se tienen las más peculiares formas textuales y aunque los términos que se usan en ellos proceden de otros ámbitos de especialidad, tales como el geográfico, el histórico, el gastronómico, etc., son destacables las recurrentes combinaciones de estos términos con adjetivos con valor ponderativo. Por nuestra parte, hacemos notar el sentido figurado de los títulos de estos folletos. A continuación los enumeramos indicando el tipo turístico que se promociona:

- Hoy me siento pez (Turismo de sol y playa)

- Hoy el gusto es mío (Turismo gastronómico)

- Hoy estoy curioso (Turismo cultural)

- Hoy estoy que no paro (Turismo activo y buceo)

- Hoy estoy rural (Turismo rural)

- Hoy me siento bien (Turismo de salud y belleza)

Los folletos se inscriben en el marco de una campaña que fue motivo de gran polémica, debatida incluso en un pleno de la Asamblea Regional de Murcia el 18 de febrero de 2009 (recogido el debate en el Diario de Sesiones de 2009, $n^{\circ} 40$ ), poco después de un mes de su comienzo. En esta campaña se encuentran también, junto a estos textos distribuidos a través de Internet, una serie de anuncios, algunos de ellos distribuidos en prensa y otros colocados en la vía pública en soporte cartel, que formaron parte de la campaña. En nuestra opinión, la recepción del anuncio incitaba al usuario a obtener mayor información del lugar en la red. Todos ellos nos muestran la estrategia institucional para la promoción del destino turístico, que tenemos que tener presente para comprender la funcionalidad de los enunciados figurados. Por esta razón, hemos seleccionado algunos anuncios y carteles para el análisis con el fin de mostrar su coherencia con la idea que guía la campaña.

4 Calvi (2010: 18) agrupa las prácticas sociales del turismo y sus correspondientes producciones textuales en tres bloques: 1) reflexión teórica sobre el turismo y sus características; 2) gestión; 3) descripción y promoción del destino turístico. 


\subsection{Hipótesis y objetivos}

Nuestra hipótesis de partida para el análisis es que los enunciados figurados presentes en los textos proyectan una imagen del destino turístico que implica para su interpretación la activación de procesos cognitivos y de valores afectivos del destinatario. La imagen de un destino "consiste en la interpretación subjetiva de la realidad realizada por el turista, interviniendo en su formación tanto elementos cognitivos como afectivos" (Bigné et alii 2007: 60). Como han señalado Hidalgo Alcázar et alii (2012: 367), el componente cognitivo de la imagen de un destino turístico está constituido por las creencias y conocimientos del individuo sobre los atributos de este destino, mientras que el componente afectivo lo conforman sus sentimientos hacia el lugar y sus motivaciones para su elección. Metáfora y metonimia, como procedimientos privilegiados del sentido figurado, guían un proceso de interpretación por parte del destinatario focalizando en los atributos del lugar que se promociona, por lo que se potencia su implicación cognitiva y afectiva. Como señalan Gallarza, Gil y Calderón (2002: 53), el primer factor que apoya la naturaleza múltiple de la imagen de un destino es la existencia de la multiplicidad de atributos sobre los que se basa. De este modo, la imagen del destino resultado de dicha interpretación conecta los llamados atractivos turísticos del lugar con las expectativas personales del turista potencial, lo que es determinante para la elección del producto.

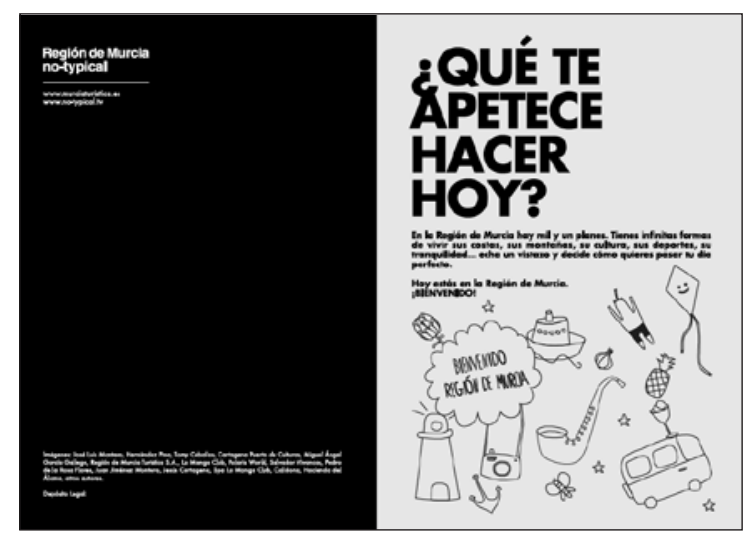

Imagen 2

Estos textos tienen una finalidad, evidentemente, persuasiva, puesto que están ligados a la actividad del marketing turístico, pero son textos híbridos, de tipo descriptivo y de tipo argumentativo al mismo tiempo. En cuanto a su función persuasiva, como sucede en el texto publicitario, se tienen distintas estrategias, compartiendo con el texto publicitario la presentación de un eslogan sugerente que activa múltiples interpretaciones, pero queremos subrayar la vinculación que se establece con la marca Región de Murcia no-typical. Para ello, en el siguiente apartado damos cuenta de la creación de esta marca, para centrarnos después en el análisis de eslóganes y anuncios.

El objetivo principal de nuestro trabajo es observar la activación del componente cognitivo y afectivo que tiene lugar en el proceso de interpretación de los enunciados figurados 
presentes en textos turísticos promocionales que se categorizan, por su configuración lingüística, como textos publicitarios. Secundariamente, veremos cómo se articula el racional creativo de la marca Región de Murcia no-typical en los distintos enunciados para lograr la finalidad comunicativa que se pretende por parte de la institución.

\section{Metodología}

Para mostrar la funcionalidad de los enunciados figurados en el texto turístico promocional que nos ocupa, realizamos un análisis semántico-pragmático de algunos casos presentes en nuestro corpus. No se pretende un análisis cuantitativo de usos figurados, sino mostrar cómo se conecta la configuración enunciativa a la función comunicativa que se quiere privilegiar. Metáfora y metonimia no pueden concebirse localmente, en una palabra, como se pretendía en el enfoque retórico, presente también en la teoría lingüística que definía la metáfora como sustitución, por lo que asumimos una teoría enunciativa del sentido figurado (Tamba-Mecz 1981). Por una parte, los trabajos de la semántica estructural nos proporcionan algunas herramientas teóricas y metodológicas para realizar el análisis semántico; así, tenemos presente el análisis del significado de Greimas (1966). Sin embargo, es fundamental en nuestra investigación la teoría de la metáfora y la metonimia desarrollada por Le Guern (1973), en la que, a partir de la nueva concepción de los tropos que se inaugura con Jakobson $(1956)^{5}$, se conjuga el análisis semántico estructural con los aspectos cognitivos de ambos procedimientos lingüísticos. Bonhomme $(1987,1998)$ sigue esta dirección, pero complementa su estudio focalizando en la intención comunicativa, lo nos que permite una aproximación pragmática. Introducimos también el enfoque pragmático de Sperber y Wilson (1986), considerando su concepto de inferencia contextual, y la revisión que de esta teoría hace Vega (2007) para explicar la interpretación del sentido figurado. En definitiva, aplicamos una metodología heterogénea, acorde con la complejidad del objeto de análisis, integrando las bases metodológicas de distintos modelos teóricos.

\section{La campaña del no-estereotipo}

En enero de 2009 el entonces Consejero de Cultura y Turismo de la Región de Murcia, Pedro Alberto Cruz, presenta la puesta en marcha de una nueva campaña impulsada por la Comunidad Autónoma para la promoción turística y cultural de la Región. En una primera fase de esta campaña, el objetivo es buscar estereotipos que identifiquen a la Región de Murcia, para lo cual se anuncia en todos los medios informativos ${ }^{6}$ que se ha contratado al reputado antropólogo Vladimir Karabatic, creador del eslogan typical spanish y responsable de convertir la paella en icono de Valencia, entre otros méritos. También se da noticia de que de forma inminente estará disponible la web www.murciaencuentrasuestereotipo. com (hoy ya no accesible), en la que se va a dar cuenta de todo el proceso de investigación de este científico de origen croata y en la que el ciudadano podrá participar en el estudio opinando y aportando ideas sobre los estereotipos de la Región. En palabras del Consejero,

5 La teoría de la metáfora y la metonimia desarrollada a partir de que Jakobson postula la estructuración del lenguaje en dos polos, el metafórico y el metonímico, vinculados, respectivamente, a los ejes paradigmático y sintagmático, redefine los tropos como procedimientos lingüísticos y no como meras operaciones retóricas.

6 Véase, por ejemplo, la noticia en el portal independiente Murcia.com: http://goo.gl/dh52Nv 
se trata de "un proceso de construcción colectiva en donde todos van a poder participar en la construcción real de una imagen real de la Región de Murcia", cuyo objetivo es generar una "expectación sin precedentes" tanto a nivel regional como nacional, a propósito de la imagen turística de la Región de Murcia. En FITUR 2009 se presenta esta campaña, con la presencia de Karabatic.

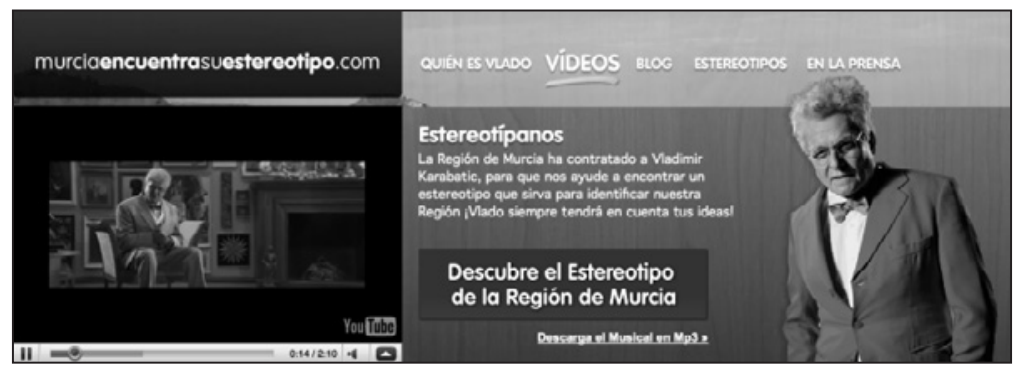

Imagen 3

$\mathrm{Al}$ poco tiempo, se descubre que es una estrategia de marketing viral, pues Karabatic es un personaje ficticio, interpretado por un actor. La farsa, apoyada institucionalmente, fue motivo de enfado tanto de políticos como de algunos medios de comunicación, que se sintieron manipulados y cuestionaron el engaño en tanto que afectaba a la imagen de Murcia y su credibilidad. A mediados de marzo de 2009, el Consejero, Pedro Alberto Cruz, presenta las conclusiones de la investigación de Karabatic: Murcia no tiene estereotipo y comienza la segunda fase de la promoción turística, si bien Karabatic continúa con su papel, aunque ya se ha descubierto su impostura y se ha borrado de Wikipedia el artículo fraudulento que sobre él se colgó el 30 de enero ${ }^{7}$. Se anuncia el certamen Región de Murcia: No-typical, organizado por la Consejería y Jameson Notodofilmest, para premiar los vídeos en los que se proyecte una imagen no estereotipada de la Región. Así, la primera fase de la campaña Murcia encuentra su estereotipo, da como resultado el eslogan Región de Murcia, no typical, que sustituye al anterior, Región de Murcia, donde vive el sol, pues Karavatic concluye que es tal la diversidad de la Región, que no puede reducirse a un cliché, a un estereotipo ${ }^{8}$. En un comunicado, la Consejería declaraba su apuesta por una Región "orgullosa de su diversidad y no reducida a un cliché, una Región No-Typical en cuanto a su gastronomía, socialmente, culturalmente y también en la forma de contarlo". La web, en esas fechas, había recibido más de 93.000 visitas $^{9}$.

\footnotetext{
7 http://goo.gl/1eD3Ff

8 En distintos medios, como La Razón, se publicó este resultado: http://goo.gl/UyrCsg

9 David Briones, creativo de la agencia murciana Germinal Comunicación, responsable de la campaña, nos ofrece en su página personal (http://goo.gl/qeeuLT) los siguientes datos: "251.000 visitas a la web; más de 300.000 visionados de los vídeos; 1.900 estereotipos propuestos; más de 8.000 referencias de Karabatic en internet y más de 10.000 de la web y la campaña. Karabatic apareció en cerca de una veintena de debates, coloquios y programas de televisión; se habló de la campaña en diarios nacionales y regionales de prensa escrita y digital, en cerca de 1.100 blogs y se creó un club de fans de Karabatic en Facebook. Por otro lado, instituciones como la Universidad de Murcia, la Universidad Rey Juan Carlos de Madrid o la Escuela de Negocios de Buenos Aires se han interesado por la campaña para utilizarla como caso de estudio".
} 


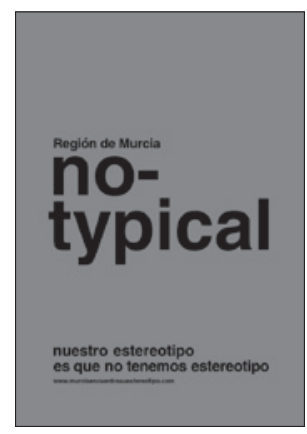

Imagen 4

En abril de 2009 el eslogan figuraba en una lona gigantesca que colgaba en la fachada de un edificio histórico de la Gran Vía en Madrid.

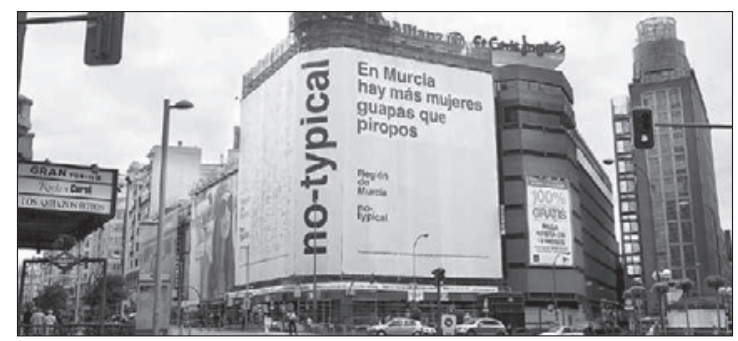

Imagen 5

El triunfo de un eslogan en el que se potencia la ausencia de tipicidades, dio ocasión para crear una serie de textos alusivos a estereotipos de otras comunidades ${ }^{10}$, como la fabada como estereotipo de Asturias, la Pilarica como estereotipo de Aragón, o el camino de Santiago como estereotipo de Galicia.

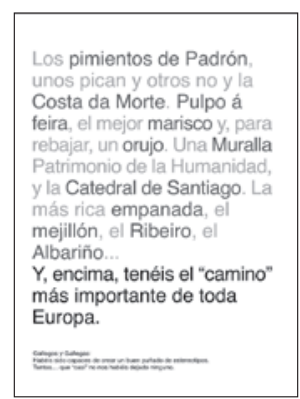

Imagen 6

10 La introducción en la campaña de una serie de textos simétricos mostrando los estereotipos de otras comunidades, fue motivo de disgusto entre las autoridades de dichas comunidades, como es el caso del alcalde de Toledo (http://goo.gl/oXlVW6). 
El 4 de enero de 2012, el Consejero anuncia la sustitución de la campaña no-typical por otra cuyo eslogan es: Destino Región de Murcia, donde operan los conceptos: destino, descubrir, relax, disfrutar, aprender y diversión. El 19 de febrero de 2014, presenta el nuevo portal www.murciaturistica.es, renovado después de diez años, con la marca Destino Región de Murcia, que sustituye a Región de Murcia no-typical, explicando: "Hemos pasado del cómo es al qué es; del adjetivo al sustantivo". Como señalan Aires Barroso y Nicolau Mota (2010: 246), la marca, como elemento destacado del marketing de un destino turístico, debe despertar el deseo del consumo.

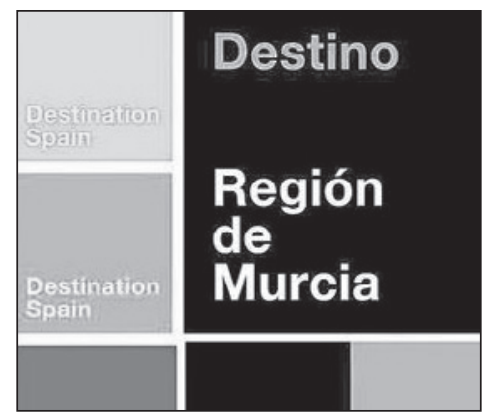

Imagen 7

Los documentos de nuestro corpus de partida se englobaron en la campaña anterior en la sección Qué hacer, mientras que en última los atributos que se promocionan aparecen en la sección Disfrutar.

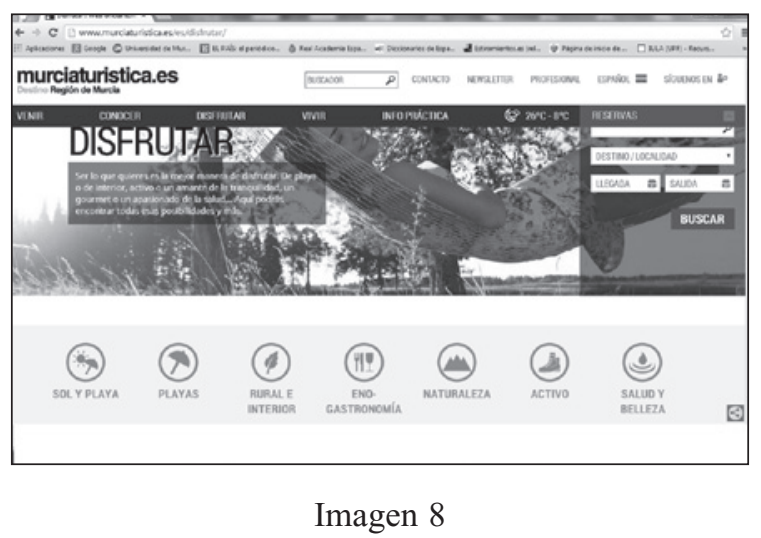

En este momento, cabe cuestionarse cuál es la concepción turística de Murcia en esta campaña, cuáles son los conceptos clave, qué se promociona y, sobre todo, cuál es la idea motor de los textos: frente al estereotipo, en la Región de Murcia está la variedad. Aunque el eslogan es Región de Murcia, no-typical, hay una serie de bienes del lugar y para cada uno tenemos un documento, como el que se titula Hoy me siento pez, un folleto que potencia el turismo de sol y playa, pero focalizando en el ahora. Es un enunciado atractivo y 
sorprendente, cumpliendo con el papel de gancho del eslogan publicitario, que se centra en las apetencias en el momento presente, del hoy. Estos folletos, presentados simultáneamente en la web, crean el efecto de diversidad que se pretende ofrecer y, al mismo tiempo, cada uno de ellos capta la atención de aquel turista que busque solo un determinado producto, sea turismo de sol y playa, turismo rural, turismo cultural, turismo gastronómico, etc. Se pretende comunicar que durante la estancia en Murcia, se tendrán posibilidades diversas, según diversas apetencias puntuales, y todas pueden verse cumplidas. Por esto se presenta la colección de folletos de forma separada, pero unidas por ese hoy, que actúa como nexo que nos invita a disfrutar cada una de las oportunidades de disfrute que ofrece esta tierra: Hoy me siento pez; Hoy estoy rural; Hoy el gusto es mío; etc. La organización del turismo ha variado y no se reduce a los períodos vacacionales, de modo que se propicia la promoción de viajes para distintos tiempos de ocio, como fines de semana. Por esta razón también se tiene en estos textos promocionales una apuesta por el hoy, que exige una menor inversión económica y de tiempo que las típicas vacaciones.

Aparentemente, la promoción turística en la actualidad no puede apostar por estereotipos, cuando el potencial turista busca nuevas experiencias y sensaciones, pero no se puede renunciar a una imagen de una Región que capte al usuario que decide un destino turístico focalizando en un bien o valor particular que identifica el lugar. La creación de la imagen de un lugar forma parte del marketing turístico, siendo el primer paso para la construcción de esta imagen la identificación de los atractivos turísticos (Aires Barroso y Nicolau Mota 2010: 250). En la campaña Región de Murcia no-typical, cada atractivo turístico se corresponde con las distintas categorías de la sección Qué hacer.

\section{Hoy me siento pez: análisis de enunciados metafóricos y metonímicos}

Si hemos de valorar la mayor o menor presencia de la metáfora en los textos turísticos institucionales, hemos de ser precavidos, pues son fundamentalmente descriptivos, si bien, como hemos dicho, también argumentativos, por la intención persuasiva dado el carácter promocional de los textos. Por ello hemos de advertir que encontramos el uso de metáforas principalmente en eslóganes y en textos concebidos como anuncios publicitarios, mientras que en el cuerpo de los folletos que analizamos se acude a otros recursos para causar impacto, principalmente la adjetivación valorativa ${ }^{11}$. La metonimia, en cambio, es más frecuente, por ser un procedimiento que incide sobre lo referencial, a diferencia de la metáfora, que incide sobre la sustancia semántica: "la metonimia completa la función referencial normal del lenguaje, superponiendo a la designación de la realidad descrita una información sobre la forma especial en que el hablante concibe esa realidad" (1980: 89). Es lo que sucede en la metonimia sol y playa que forma parte ya de la lengua del turismo (turismo de sol y playa, destino de sol y playa).

11 Esta adjetivación da lugar a la creación de nuevas denominaciones en la lengua del turismo, como hotel familiar, si bien estos nuevos términos representan conceptos que el hablante desconoce y que aún no se recogen en los repertorios lexicográficos, ni siquiera en los especializados (Sanmartín 2012: 90). A propósito de la praxis lexicográfica, apuntamos también, como señala Azorín (2015) que la selección de voces depende, entre otros factores, del criterio valorativo del lexicógrafo, de la idea de lengua que maneje, lo que es especialmente relevante en el caso de los neologismos. 
Ciertamente, en los folletos de la sección Qué hacer de la web, así como en los anuncios distribuidos en prensa, lo más destacable es la adjetivación; así, en el folleto Hoy me siento pez, solo en una de sus páginas, la subtitulada Hoy te bañas en la Costa Cálida, encontramos: extensas arenas claras, tranquilas aguas, paraísos casi inalterados, la costa más abrupta, calas vírgenes, puntas rocosas, excelentes playas de fin arena, suaves temperaturas, espacios increíbles. Sin embargo, como decíamos, en aquellas partes textuales que se identifican como propias de la argumentación, más que de la descripción (eslóganes y anuncios), se recurre a la producción de enunciados figurados, a veces complejos, con superposición de metáfora y metonimia. En el cuerpo de los folletos los usos creativos se introducen en menor medida, dado que, como hemos señalado, es predominante una adjetivación valorativa. Por tanto, en consonancia con su finalidad, estos textos integran una adjetivación apreciativa en el plano de la descripción y, al mismo tiempo, metáforas y metonimias, en el plano de la argumentación.

\subsection{Análisis de eslóganes en los folletos turísticos}

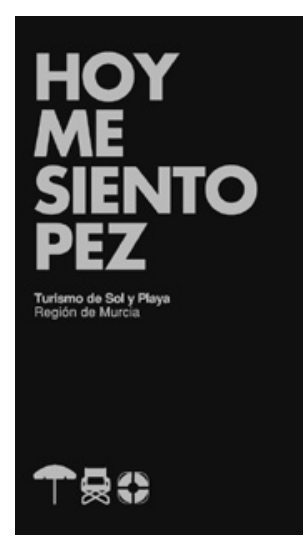

Imagen 9

Nos centramos en el análisis de dos de los títulos: Hoy me siento pez y Hoy el gusto es tuyo, que, a nuestro parecer, son los más sorpresivos, por lo que son ejemplos señeros para mostrar la implicación intelectual y afectiva del receptor para su interpretación.

El eslogan Hoy me siento pez aparece en la primera página del folleto; en la segunda página, cuando comienza el texto, se cambia a la segunda persona: Hoy te sientes pez. Del mismo modo sucede en los otros documentos: en el folleto Hoy el gusto es mío, dedicado al turismo gastronómico, se pasa a un discurso dirigido al tú, turista potencial: Hoy el gusto es tuyo. En el primero de los enunciados tenemos la metonimia pez por mar, pero se solapa con la imagen metafórica que subyace en la unidad fraseológica sentirse como pez en el agua. La metonimia aquí desempeña la función comunicativa que Bonhomme (1987: 127) denomina individualizadora: se denota el referente mar de forma oblicua, focalizando en uno de los polos denotativos que forma parte, por contigüidad, del dominio semiótico de mar. En el segundo enunciado tenemos también una metonimia: el sentido del gusto por el turismo gastronómico; en este caso, cumpliría con la función deceptiva que Bonhomme señala para 
este tropo (1987: 159), por cuanto que se tiene una incertidumbre referencial, una ambigüedad contextual, que después analizaremos. No obstante, el propósito es la focalización en lo sensitivo, lo que aparece explícitamente en el eslogan que encontramos en otro documento de interés de la web dedicado a las rutas enoturísticas: Una experiencia para los sentidos.

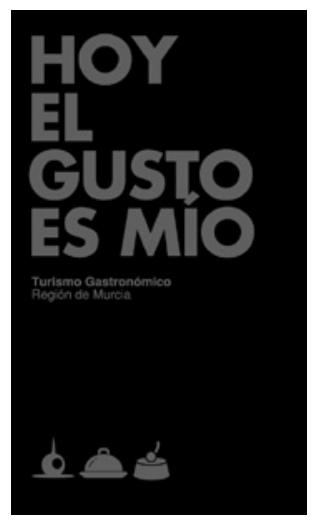

Imagen 10

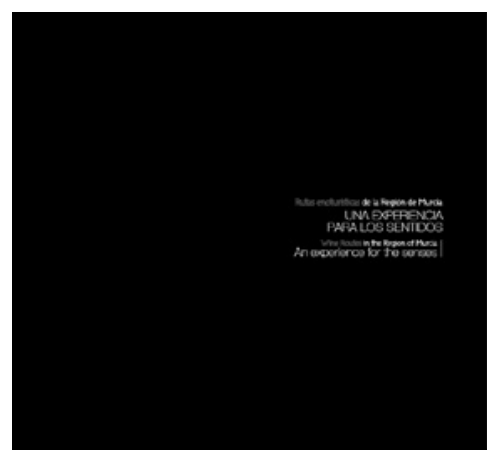

Imagen 11

Para examinar la funcionalidad de estos usos en el texto turístico conviene un análisis semántico y pragmático que integre los distintos aspectos que intervienen en la producción e interpretación del sentido figurado. Aunque en primer lugar, desde el punto de vista cognitivo, hemos considerado que el sentido figurado en el enunciado Hoy me siento pez sucede contextualmente por metonimia, también podemos interpretar el enunciado como una metáfora nominal del tipo N1 es un N2 en la medida que sentirse se considera un verbo semiatributivo. Este tipo de enunciados metafóricos, que Tamba-Mecz (1999) analiza ilustrando con une femme est une fleur, no constituyen enunciados clasificatorios basados en la inclusión o pertenencia a clases, sino que, por el contrario, bloquean propiedades de clase para remarcar una propiedad. En Hoy me siento pez, por otra parte, el complemento predicativo que aparece con este verbo semiatributivo es un sustantivo concreto, cuando al verbo sentir tendría que seguir un elemento léxico con el clasema [+abstracto]; además, aparece 
un sustantivo en lugar de un adjetivo, que sería lo esperable, puesto que, aunque es posible la construcción sentirse + [sustantivo], la construcción prototípica en español es sentirse + [adjetivo]. Lo anterior sería un índice discursivo en el plano gramatical de la presencia de una figura, que se suma al índice en el plano semántico que viene dado por la conexión de dos dominios conceptuales distintos: sentimiento (abstracto) y seres vivos (concreto). La ruptura clasémica que se produce en el enunciado por la presencia de pez en un contexto no habitual para esa ocurrencia léxica es lo que procura, según Moreno Villanueva (1993: 198), una gran fuerza expresiva, pues el oyente descubre contextos "imaginables" en lugar de los contextos "normales".

Por otra parte, en el enunciado Hoy me siento pez podemos interpretar una modificación de la unidad fraseológica sentirse como pez en el agua, si bien, como hemos visto, también puede concebirse como enunciado figurado al margen de esta expresión prefijada y convencional. El sentido figurado de sentirse como pez en el agua, y de su variante estar como pez en el agua, nos remite a una sensación de satisfacción o disfrute en algún medio o lugar, en alguna circunstancia o situación, que se asimila a nuestro medio natural ${ }^{12}$. Quizás esta asociación, que podría ser no consciente, hay que evaluarla como un valor connotativo que se suma al enunciado. Sin embargo, subyace la imagen, como lo corrobora el hecho de que en la actual campaña Destino Región de Murcia, la promoción de Murcia como destino de sol y playa se presenta como una reescritura de los textos de esta campaña anterior que estamos analizando. Presentamos los enunciados de una y otra campaña relacionados:

Campaña Región de Murcia no-typical: Hoy te bañas al sol. [...] Hoy descubres una cala y le pones tu nombre. [...] Cambia la sombrilla por el traje de neopreno y el flotador por alguna actividad acuática mucho más aerodinámica.

Campaña Destino Región de Murcia: Bañarse al sol en playas de arena, bautizar calas escondidas, desafiar al viento sobre una tabla o cambiar la sombrilla por el traje de neopreno son sólo algunas de las opciones que tenemos para que te sientas como pez en el agua.

Por tanto, además de la metonimia pez/mar (relación de contigüidad entre la entidad y su lugar, incluso metonimia del continente por el contenido), está la analogía entre el hábitat natural del pez, que es el mar, con el hábitat del individuo, que se construye en Hoy me siento pez como metáfora nominal a partir de la asociación con sentirse como pez en el agua (téngase presente la expresión antónima: estar/sentirse como pez en el agua). La metáfora nominal que interpretábamos anteriormente en Hoy me siento pez, se localiza en pez, sino en todo el enunciado, pues no estamos ante una sustitución, sino ante una imagen creada en virtud de una analogía que se desprende del contexto enunciativo en el que aparece pez y sumando la competencia fraseológica del hablante ${ }^{13}$. La complejidad, como vemos, es alta, lo que motiva la implicación del destinatario en el proceso de interpretación del sentido figurado. Ello es propio de los textos publicitarios, como ya hemos señalado en otra ocasión:

12 Otra unidad fraseológica que presenta la forma pez es estar pez (en alguna materia), pero no la consideramos porque no responde a la intención comunicativa del enunciado que analizamos.

13 El enfoque sustitutivo y comparativo en la teoría de la metáfora fue puesto en cuestión por Black, quien propone un enfoque interactivo inspirándose en Richards: “decir que la metáfora crea la semejanza sería mucho más esclarecedor que decir que formula una semejanza que existiera con anterioridad” (1966: 47). 
La elección, por parte del creativo publicitario, de un significante que no lleve directamente a la referencia -que es lo que sucede en los signos "automatizados", y que es lo que la publicidad quiere evitar a toda costa-, conduce, necesariamente, a un ejercicio interpretativo. Ayuda a que una construcción sea memorable el que se proponga un juego interpretativo, de tipo inferencial, que implique el razonamiento del destinatario. Ello es así porque ese juego forma parte de nuestros procesos cognitivos y por tanto es creador de conocimiento (Corrales, 1999: 120). Por otra parte, esta implicación, este juego, nos lleva a la dimensión lúdica del discurso publicitario, que estaría en relación -cómo no- con el delectare clásico, el combate contra el tedio. Es el placer del conocimiento (Sánchez Manzanares 2003: 746).

Los efectos cognitivos que resultan del uso figurado en el plano cognitivo son más claros o fuertes cuanto mayor sea la innovación, puesto que el proceso inferencial implica la reconstrucción de mayor número de elementos contextuales. En la perspectiva de la teoría pragmática de la relevancia de Sperber y Wilson (1986), se diría que en los enunciados figurados hay un conjunto de supuestos que están contextualmente débilmente implicados. No obstante, la comprensión no puede dificultarse en exceso en el texto turístico, puesto que se pretende motivar una determinada elección, por lo que se tendrá presente el conocimiento compartido. En este sentido, las locuciones, como cápsulas informativas del acervo cultural de una comunidad, resultan adecuadas, incluso cuando se modifican o cuando están solamente sugeridas, como en el caso de sentirse como pez en el agua; además, como señala Guiraud (1967: 57), en las locuciones se tienen empleos figurados a partir de observaciones cotidianas, lo que facilita la comprensión.

En el caso de Hoy el gusto es mío, se tiene también un juego interpretativo con la fórmula rutinaria para una presentación El gusto es mío, que forma parte de nuestro repertorio fraseológico. Como señalamos anteriormente, tenemos una metonimia (el sentido del gusto por el turismo gastronómico), pero, en este caso, la unidad fraseológica no favorece la interpretación del sentido figurado. El propósito del eslogan es, por el contrario, funcionar como gancho que golpea al destinatario para interesarlo por el sentido, que se resuelve en la leyenda situada bajo él, en caracteres bastante más pequeños: Turismo gastronómico. De la misma manera que en los textos humorísticos los indicadores que tienen que ver con la polisemia y la ambigüedad son los más rentables (Ruiz Gurillo 2014: 160), así sucede en los textos publicitarios, puesto que en ambos se pretende la sorpresa. Es la función deceptiva que mencionamos anteriormente para esta metonimia, cuyos indicadores son la polisemia de gusto y la ambigüedad contextual, más aún cuando se juega con una fórmula cuya ilocución está prefijada. Esta incertidumbre referencial incide en la "literariedad" del mensaje, en la atención a la misma constitución formal del mensaje, lo que es característico del eslogan publicitario. La función "poética" de la metonimia ha sido señalada, entre otros, por Le Guern (1980: 89) y es un efecto del desplazamiento referencial que se produce con este tropo, que conduce, en este caso, a una focalización sobre la materialidad de la propia lengua.

\subsection{Análisis de enunciados en anuncios}

\subsubsection{Anuncios en prensa}

Es necesario un conocimiento del contexto cultural para comprender la descripción que de la Semana Santa se hace en un texto como el que sigue: 


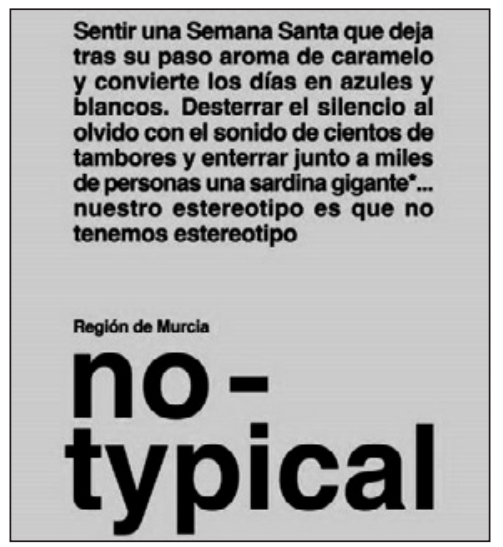

Imagen 12

En el primer enunciado, cuando se nos dice que la Semana Santa deja tras su paso aroma de caramelo, primeramente, tenemos el juego con la polisemia de paso, puesto que, además de su sentido en el seno de la construcción dejar tras su paso, también se actualiza el sentido de paso como el trono con las imágenes que se procesiona en Semana Santa. En segundo lugar, y aquí es donde cabe el conocimiento del contexto cultural para la comprensión del enunciado, aroma de caramelo alude al hecho de que en las procesiones de nuestra Región es típico que los que procesionan repartan caramelos al público espectador. En cuanto a los días que se convierten en azules y blancos, se hace referencia a las procesiones de Lorca, donde hay dos cofradías, la de los blancos y la de los azules -a su vez, metonimias por el color de la túnica de los penitentes-, que muestran su rivalidad efusivamente durante los actos de la Semana Santa. Es claro que sin estos datos contextuales, no se llegará a una interpretación completa del enunciado, pero para nuestro análisis, lo que nos interesa es que la Semana Santa (metonimia por los actos que tienen lugar en ese tiempo) se muestra con atributos materiales, como el aroma. Tenemos la representación de la Semana Santa como un bien tangible mediante un proceso metafórico tan natural como complejo. La metáfora hace sensible lo no perceptible y lo que se pretende es hacernos sentir la Semana Santa, como se nos dice explícitamente.

El enunciado resulta poético, por las imágenes que despierta la sugerencia del aroma de los caramelos y los días blancos y azules, incluso si se desconocen los elementos culturales. Ello tiene que ver, por una parte, con la selección léxica, que suma valores connotativos positivos: aroma, caramelo, blanco, azul, todos ellos añaden un valor subjetivo positivo que se suma al valor propiamente denotativo. Pero es en la configuración final del enunciado que se tiene una imagen sugerente, que transmite sensaciones incitantes, atractivas. Ese es uno de los objetivos del enunciado: promocionar sensaciones, vivencias, emociones, que satisfagan las expectativas del turista actual. El otro es la reformulación de estereotipos a base de la representación no convencional de los atractivos turísticos de la Región, de acuerdo con la marca no-typical.

La metáfora nos ofrece una visión diferente del producto, destaca un aspecto o atributo del mismo de un modo novedoso, procurando una impresión de frescura, una originalidad 
que es fruto de una aprehensión del mundo desde una óptica no convencional. Para Le Guern, la metáfora suspende la significación lógica y despierta en el receptor una imagen que lo implica en un proceso de interpretación en el que accede a una significación impuesta por el contexto, que priva a la imagen asociada de su carácter arbitrario. No obstante, no es preciso que el receptor sea consciente de esa imagen en el nivel de la inteligencia lógica:

Ahí se encuentra el carácter específico de la metáfora: al obligar a abstraer a nivel de la comunicación lógica cierto número de elementos de significación, ella permite poner de relieve los elementos mantenidos; a un nivel distinto del de la pura información, y por medio de la introducción de un término extraño a la isotopía del contexto, provoca la evocación de una imagen asociada que percibe la imaginación y que ejerce su impacto sobre la sensibilidad sin el control de la inteligencia lógica, pues la naturaleza de la imagen introducida por la metáfora le permite escapar a él (1980: 25).

Así, además, es más eficaz la persuasión (Le Guern 1980: 85), por cuanto no puede haber oposición desde la lógica intelectual.

Por otra parte, en el segundo enunciado del anuncio, la primera parte, Desterrar el silencio al olvido con el sonido de cientos de tambores ${ }^{14}$, el sentido figurado resulta de una personificación por metáfora del silencio. No obstante, lo usual es que lo personificado aparezca como sujeto de la acción relatada en el enunciado y tenemos este recurso de forma recurrente en enunciados que encontramos en el interior de los distintos folletos de la sección Qué hacer. Así, por ejemplo, podemos observarlo en el enunciado Hoy las olas te mecen con cariño y el viento te cuenta secretos al oído, presente en la siguiente página del folleto Hoy me siento pez:

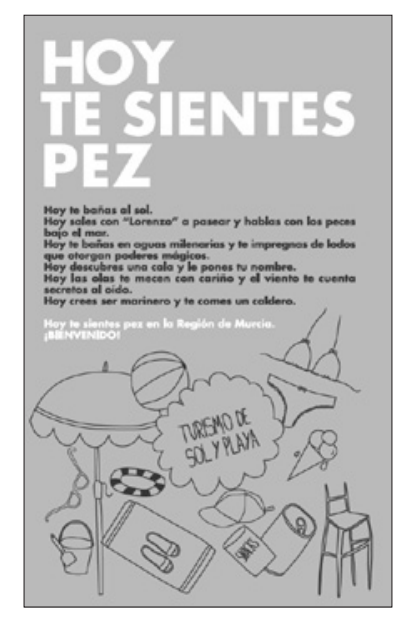

Imagen 13

14 La segunda parte del enunciado: enterrar junto a miles de personas una sardina gigante, motiva la interpretación de la participación del destinatario en un acto que es, en realidad, un acto simbólico: la celebración del entierro de la sardina tras la Semana Santa. 
Como nos dice Prandi, un verbo puede usarse metafóricacmente de dos formas: "pour opérer une classification conflictuelle d'un procès - par exemple, un acte de parole est catégorisé comme une instance de chant- ou pour entraîner des actants conflictuels dans un procès: des êtres inanimés comme les montagnes, par exemple, se voient attribuer le procès du sommeil" (Prandi 2002: 11). En el enunciado Dorment les sommets des montagnes, en el que se aplica al verbo un sujeto conflictual, observa Prandi que el sujeto virtual coherente con el verbo, el ser animado, se proyecta sobre el sujeto virtual, las montañas, como un sujeto subsidiario, de manera que los dos sujetos forman un paradigma interactivo, no sustitutivo. La única función admitida por este paradigma es, en la perspectiva de Prandi, enmarcar una proyección de los seres vivos sobre las montañas (Prandi 2002: 12). Del mismo modo, en nuestro enunciado se proyecta el ámbito de la acción humana sobre las olas y el viento.

Para Lausberg (1991: 64, § 559), esta figura es la "forma más penetrante de la metáfora sensibilizadora". La transferencia entre los rasgos semántico-referenciales inanimado/ animado se interpreta como una de las constantes psicolingüísticas del proceso metafórico. Estas metáforas para la personificación suponen una incompatibilidad combinatoria en el plano semántico y una proyección de atributos en el plano cognitivo.

\subsubsection{Carteles}

Por último, analicemos algunos enunciados comparativos que proyectan el sentido figurado presente en la metáfora sobre la que se construyen ${ }^{15}$. Se inscriben en los textos que se exhibieron en las lonas publicitarias que colgaron en fachadas de ciudades principales, como Madrid.

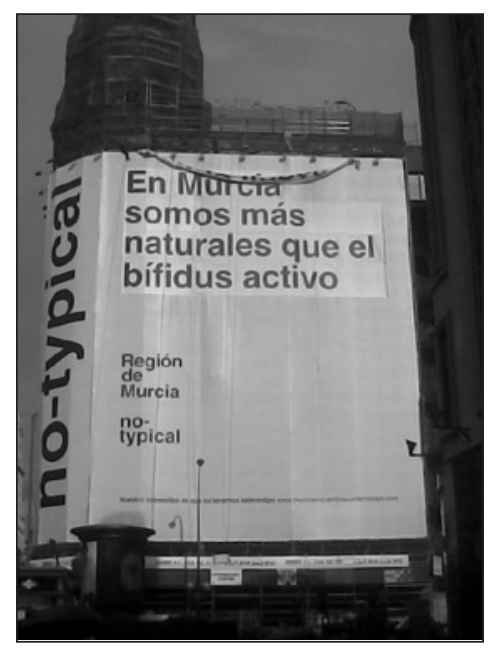

Imagen 14

15 Otras estructuras comparativas que encontramos en la campaña son hipérboles, como En Murcia hay más mujeres guapas que piropos. También tenemos una estructura comparativa que resulta de la modificación de un eslogan publicitario muy conocido en la comunidad española: En Murcia la primavera llega antes que al Corte Inglés, para significar el clima cálido de la Región. 
El enunciado En Murcia somos más naturales que el bífidus activo es una estructura comparativa que se sustenta en la metáfora: Murcia es un producto natural; esta metáfora sustenta una estructura comparativa mediante la cual se consigue una intensificación del atributo que se pretende potenciar. La finalidad de estas estructuras comparativas es focalizar la atención del receptor en aquello que se quiere hacer relevante y ello se consigue mediante la intensificación del atributo que se pretende potenciar. La metáfora, como nos dice Le Guern (1980: 47), pone de relieve el atributo dominante que, en la imaginación del hablante, comparten los "objetos" entre los que se establece la analogía, de manera que por la metáfora se consigue una sobresignificación cuyo efecto es una gran fuerza expresiva.

Si estas estructuras comparativas se fundamentan en estereotipos, como es el caso de más negro que el carbón, tendrán una base cultural (el carbón como prototipo cultural de la negrura) y una base semántica (presencia del sema 'negro' en el significado de carbón) (García Page 2008: 146). En nuestro caso, el atributo sobresaliente del bífidus activo de 'producto natural' es una creencia que se ha impuesto recientemente en nuestra cultura, por lo que la comparación resulta original y llamativa, al mismo tiempo que divertida. El carácter lúdico de estos textos para la promoción de la Región de Murcia es evidente; precisamente la función lúdica de la metáfora, por el juego interpretativo, es otra de las funciones de este procedimiento que se suele valorar en los textos creativos.

\section{Conclusión}

El concepto de turismo ha evolucionado, así como el concepto de imagen de destino (Andrade 2012: 478), centrándose la promoción de un destino en las vivencias y emociones del potencial turista. El análisis de enunciados figurados en distintos textos de corte publicitario de la campaña turística Región de Murcia no-typical, promovida institucionalmente, nos ha mostrado la intervención de metáfora y metonimia en la creación de la imagen del destino turístico. Las bases metodológicas que sustentan este análisis se fundamentan en modelos teóricos de la semántica y de la pragmática que están presentes en estudios como los de Le Guern (1973) o Vega (2007).

En el marco de una campaña cuya idea clave es la apuesta por la diversidad y lo no convencional, hemos seleccionado para el análisis semántico-pragmático una serie de enunciados figurados presentes en folletos y anuncios en los que se reformulan los estereotipos vinculados a los atractivos del lugar. Específicamente, se trata de los títulos de los folletos, que se asimilan a eslóganes publicitarios, y de las leyendas de anuncios, tanto distribuidos en prensa como en carteles al modo de vallas publicitarias. Para lograr la persuasión, finalidad propia de los textos promocionales que nos ocupan, se guía al destinatario mediante estos enunciados en la construcción de una imagen de destino que crea o refuerza sus expectativas, incluso cambia sus creencias o actitudes frente al producto. Los componentes cognitivo y afectivo del destinatario se ven afectados por estos procedimientos creativos, la metáfora y la metonimia, en la medida en que lo implican en la interpretación del enunciado y le conducen a una representación subjetiva del lugar que determinará su elección. Se consigue así su adhesión, tanto a nivel intelectual como a nivel emocional. 


\section{Referencias bibliográficas}

Aires Barroso, G. y Nicolau Mota, K. C. (2010): "Marketing turístico internacional. La Marca Brasil”, Estudios y Perspectivas en Turismo, vol. 19, 2, págs. 241-267.

Andrade Suárez, M. J. (2012). "La interpretación de la realidad del destino por parte de los turistas: evaluaciones cognitivas y afectivas". Pasos, 10 (5): 477-494.

Azorín Fernández, D. (2015): “Ideología y diccionario: aspectos de la neología léxica en los inicios de la lexicografía moderna del español". En Cunita, A. y C. Lupu (eds.): Neologie, neologisme. Concepte, analize. Bucarest, Universidad de Bucarest, págs. 7-22.

Barcelona, A. y R. Rocamora (2000): "El argot turístico y la teoría cognitiva de la metáfora y la metonimia", Cuadernos de Turismo, 5, págs. 19-34.

Bigné, E.; Sánchez, I. y R. Currás (2007): “El papel de la imagen del destino en la valoración y comportamiento postcompra del turista de sol y playa", Papers de turisme, 42, págs. 57-73.

Black, M. (1966): Modelos y metáforas. Madrid, Tecnos.

Bonhomme, M. (1987): Linguistique de la métonymie. Berna, Editions Peter Lang.

Bonhomme, M. (1998): Les figures clés du discours. Paris, Éditions du Seuil.

Calvi, Maria Vittoria (2010): "Los géneros discursivos en la lengua del turismo: una propuesta de clasificación”, Ibérica, 19, págs. 9-32.

Gallarza, M.; Gil, I. y H. Calderón (2002): "Imagen del destino. Hacia un marco conceptual”, Annals of Tourism Research en Español, vol. 4, 1, págs. 37-62.

García-Page, M. (2008): "La comparativa de intensidad: la función del estereotipo", Verba, vol. 35 , págs. $143-178$.

González García, V. (2012): "El discurso del turismo en Internet: hacia una caracterización de sus géneros”. En Sanmartín Sáez, J. (ed.), págs. 13-49.

Greimas (1971 [1966]): Semántica estructural. Madrid, Gredos.

Guiraud, P. (1967): Les locutions françaises. Paris, Presses Universitaires de France.

Hidalgo Alcázar, Mª del C.; Sicilia Piñero, M. y Ruiz de Maya, S. (2012): "La imagen de destino y el contenido generado por otros usuarios: el caso del turismo rural". En Guevara, A. et alii (eds.) Actas del IX Congreso Nacional "Turismo y Tecnologías de la Información y las Comunicaciones”, TURITEC 2012. Málaga, Facultad de Turismo, págs. 365-379: http://www.turitec.com/actas/2012/Actas_Turitec_2012_Completas.pdf (15/05/2015)

Jakobson, R. y M. Halle (1980 [1956]): Fundamentos del Lenguaje. Madrid, Ayuso-Pluma.

Le Guern, M. (1980 [1973]): La metáfora y la metonimia. Madrid, Cátedra.

Lausberg, H. (1991): Manual de Retórica Literaria. Madrid, Gredos.

Moreno Villanueva (1993): "La metáfora desde la perspectiva de la Pragmática", Universitas Tarraconensis. Filologia, XIV, Tarragona.

Prandi, Michèle (2002): "La métaphore: de la définition à la typologie", Langue française, 134 , págs. 6-20.

Ruiz Gurillo, L. (2014): "Infiriendo el humor. Un modelo de análisis para el español”, clac 59/2014, págs. 148-162: http://revistas.ucm.es/index.php/CLAC/article/ view/46712/43844 (15/05/2014)

Sánchez Manzanares, C. (2003): “La metáfora en la recepción del discurso publicitario”. En Almela Pérez, R. et alii (eds.) Homenaje al Profesor Estanislao Ramón Trives. Murcia, Servicio de Publicaciones de la Universidad de Murcia, págs. 745-760. 
Sanmartín Sáez, J. (ed.) (2012): Discurso turístico e internet. Madrid, Iberoamericana Vervuert.

Sanmartín Sáez, J. (ed.) (2012): “De las normativas turísticas a las páginas electrónicas de promoción de hoteles: la clasificación hotelera desde la perspectiva lingüística”. En Sanmartín Sáez, J. (ed.), págs. 81-124.

Sperber, D. y D. Wilson (1994 [1986]): La relevancia: comunicación y procesos cognitivos. Madrid, Visor.

Tamba-Mecz, I. (1999): "La femme est-elle une fleur comme le bleuet est une fleur? Métaphore et clasification : les structures en “'Le N1 est un N2'»", en Kleiber, G. y N. Charbonnel (eds.), La métaphore: entre philosophie et réthorique. Paris: PUF, págs. 207-235.

Tamba-Mecz, I. (1981) : Le sens figuré. Vers une théorie de l'énonciation figurative. Paris, Presses Universitaires de France.

Vega Moreno, R. E. (2007): Creativity and Convention. The Pragmatics of Everyday Figurative Speech. Amsterdam, John Benjamins. 